\title{
Quality of Working Life, Knowledge-Intensive Work Processes and Creative Learning Organisations
}

Information Processing Paradigm versus Self-Organisation Theory

Klaus Fuchs-Kittowski, Frank Fuchs-Kittowski

${ }^{1}$ University of Applied Sciences Berlin (Germany), fuchs@cs.tu-berlin.de,

${ }^{2}$ Fraunhofer ISST Berlin (Germany), frank.fuchs-kittowski@isst.fhg.de

Abstract: This paper discusses the requirements that are necessary to make the organisational potentials of modern information and communication technology usable for the development of creative learning enterprises. It is shown that knowledge-intensive work processes require new co-operative, self-organising forms for work, organisation and learning that support creativity and can be supported by information and communication systems (in particular telecooperation systems). The problem is that within the framework of the information processing paradigm it is not or only insufficiently possible to treat the emergence of information. The concept of self-organisation has its justification here, because during this process information is indeed generated.

Key words: quality of work, tele-cooperation, learning organisation, knowledge creation

\section{INFORMATION CREATION WITHIN ORGANISATIONS AND CREATIVE LEARNING ENTERPRISES}

Based in the movement for the improvement of the Quality of Working Life (QWL) and the basic requirement of job enlargement and job enrichment with the aim of improving job satisfaction [Trist 1981, Jenkins 1981, Mansell 1983] are today the design of socio-technical systems [Ulich 1992, Frei et al. 1996] and an orientation toward qualification with the aim 
of guaranteeing individual and organisational learning processes for the evolution of creative learning organisations [Fuchs-Kittowski 1998a] important issues in today's global economy.

Modern information and communication systems enable new work and organisational forms. In particular, due to the relative independence of work from space and time provided by telecooperation systems the formation of flexible, team-based organisations, as well as virtual and creative learning enterprises. These, in turn, can promote personality and organisational development is possible [F. Fuchs-Kittowski et al. 1998a].

The central theoretical concept here is self-organisation. And one can only speak of self-organisation in cases where new information is created, i.e. where creative - and not just instructive learning processes - take place [Fuchs-Kittowski et al. 1998c; Fuchs-Kittowski et al. 1999a]. It demands and enables a fundamental move away from the machine/computer model of organisations towards a creative learning organisation.

The introduction of information and communication technology always involves a jump from the totality of a social organisation - an action system to the ability to design and implement function systems. However, a social system as a whole cannot be represented as a system of cybernetic functions. A transition takes place from the social organisation as a self-organising system (system of actions) to a pre-organised, formal system of functions, i.e. reduction of human activity to formalised operations and abstraction from the processes of information creation and value creation as they occur in the social organisation.

The information processing approach [cf. Simon 1997], which that arose with the Cybernetics (I order) and is represented to a large extent in computer science, especially in artificial intelligence research, has led to an understanding of the enterprise organisation alone as an information processing system. However, on the basis of somewhat deeper considerations of information and organisation theory, we - to the contrary advance the thesis that in the process of self organisation of living and social systems information comes into existence, and is not merely processed after having been introduced from external sources [Fuchs-Kttowski et al. 1998a]. This is a finding that is currently advocated particularly as the result of concepts developed in Japan and the USA about knowledge management and learning enterprise organisations [e.g. Krogh et al. 2000]. They speak about enabling knowledge creation by different transfer processes, especially from existing tacit or implicit to explicit knowledge.

Because of the increasing possibilities of practical changing, theoretical reflection and communicative actions, as basis for human cognition and knowledge creation, the increasing possibilities regarding the development of the individuality and creativity of people in and outside of the 
organisation, as well as because of the expanded possibilities for the transmission of social tradition (through objectification and reification of the knowledge in work organisation, tools, software and parts of the business culture), enterprises too are now on the way to develop creative learning organisations. This means that, on the basis of an intense interrelation with their environment, the use of internal and external information sources, they are increasingly able internally to create new information and values in the developing (self-organising) social organisation and to develop new knowledge for new actions.

\section{THE SEMANTIC OF SOCIAL INFORMATION IS GENERATED IN SOCIAL PROCESSES - SEMANTIC FEEDBACK NEEDED}

In information processing paradigm information is always already existing. It is not asked, how information develops, how it is generated. In nature information generation is connected with the development of life. Information generation occurs in the phylogenesis and in the ontogenesis of living systems [K. Fuchs-Kittowski et al. 1998c]. Information generation is also typical for developing social systems.

As SØren Brier points out, the information processing paradigm will not succeed in describing the central problem of mediation the semantic, the content of a message, "from the producer to the user, because it does not deal with the social and phenomenological aspects of cognition" [Brier 1994]. This insight is imported for a rational and human use of information and communication technologies, especially in the work processes, it is important for the understanding of certain new developments in biology, social sciences and as we see also in the library and information science.

However, if information is always regarded as a previously existing structure, then one cannot or can only insufficiently see the social and cultural processes of information creation [K. Fuchs-Kittowski et al. 1998c].

The semantic of social information is generated in a social process. When for instance a biochemist looks for literature about the therapeutic effect of COX-2 (cyclo oxygenase-2), he can find this via various descriptors. But in this context, one must take into account that the meanings of the indexes and of the retrieval concepts have not emerged in the same "language game". In most cases the social surroundings will be different in which the meanings have emerged. Thus the meaning of the words will differ that are used by the author, later by the indexer, and finally by the retriever/ user. This shows the significance of feedback effects that become possible in an enlarged or 
multiplied knowledge transfer cycle.[F. Fuchs-Kittowski 2001]. The meanings of concepts are not set out in advance, but they emerge in a social process of self-organization. Hence, if there is no feedback between this knowledge producer - the author of the document, the indexer and the user, then information/knowledge is not really produced in the system. In another case it can happen that the user receives not the correct document, but a number of documents that are useless for him.

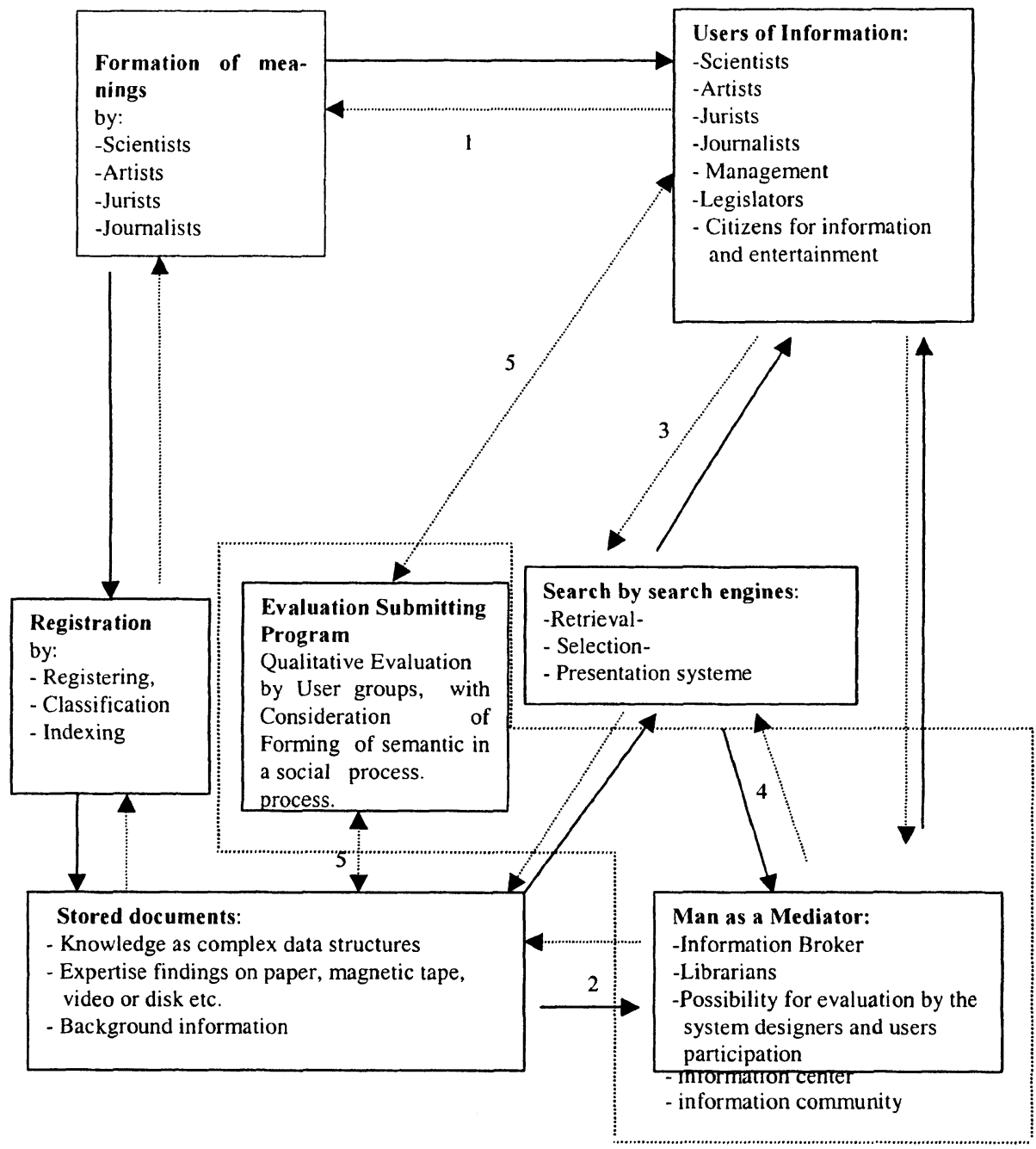

Figure 1. A Document-Disseminating Information System as a Self-Organizing System (Amended Diagram according to [Brier 1996]) 
In the social or societal organizations, communication is going on by means of generalized media, such as science and culture. Language games according to Wittgenstein or discourse communities as studied by sociolinguistics point out to the pragmatic aspects of the self-organization processes in social systems that determine the meaning of the words in the social context. These semantic fields are the really decisive means of knowledge organization and of document retrieval community [Brier 1996].

Therefore we take a diagram originally elaborated by S. Brier. He drew it up to make clear the necessary semantic feedback processes, but we add to it in particular a feedback loop of user evaluation and we stress again [K. Fuchs-Kittowski et al. 1975] the importance of Information Centers or competent Information Communities (see figure 1).

The possibilities for interaction via the Internet allow increasingly customized supplies and the formation of large communities. Now this allows the emergence of services different from the conventional search services. The novel services are consistently transferring to the competent end user or user groups the production of information and in particular the evaluation of its quality. As compared with the conventional catalogues, here each Internet user receives a possibility to evaluate the found web page or documents. This proves to be an important way to improve the quality of information by services on the Internet and intranet as well.

The diagram illustrates a document-disseminating information system as a self-organizing system by means of semantic feedback relations. The nondotted arrows illustrate the document transportation. The dotted arrows illustrate the feedback relations in the form of negative or positive evaluation of the document contents or of the system's performance.

1. It refers to the possibility of direct interaction by the circulation of documents between the producer and user. In particular, scientists do this when they dispatch off prints. In Knowledge-Co-Production producer groups are also formed in the scientific community.

2. It refers to the possibility of a librarian's direct access to a document collection. In the case of an appropriate specialization, e.g. as a biochemist / molecular biologist who continuously attends the current specialist conferences, he is suited to the language game of the biochemist/molecular biologist as a producer and user.

3. It refers to the end user's access via an online system. Here, however, the described difficulties occur in regard to the mostly differing utilization of concept meanings in the organization of science.

4. This refers to the possibilities of Man, of the librarian or information broker as a mediator of the collection or also as a system designer to support the electronic search by improving the systems. Here it is possible to improve the global quest by search engines, such as systems 
for retrieval, selection and presentation, in particular by a purposeful specialization of the data / knowledge bases.

5. With the Evaluation Submitting Program we introduce a further feedback relation, the evaluation by the competent user or user groups. In our view, this feedback loop is particularly important in semantic and syntactic terms ( $\mathrm{S}$. Brier had indeed implied it in 3 and 4, but not taken it sufficiently into account). This aspect is particularly important in the search for scientific literature, when asking for medical documents. But it also acquires a general importance for the normal user with regard to the rubbish in the Internet.

\section{KNOWLEDGE-INTENSIVE WORK PROCESSES}

Service processes in particular are increasingly customer-oriented and knowledge-intensive (as, for example, customer consultation, support and care) and require new cooperative, self-organising forms for work and organisation, as well as for learning, that support creativity [F. FuchsKittowski 2001, K. Fuchs-Kittowski et al. 1999a].

In knowledge-intensive work processes, the integration, combining and grouping of the distributed and heterogeneous knowledge available in an organisation, as well as the creation of conditions for creativity, become an important task. It is important to distinguish whether knowledge that is already available must merely be provided and integrated for the fulfilment of tasks in knowledge-intensive processes, or whether new knowledge must actually be developed.

Knowledge-intensive processes are characterised that not all knowledge relevant to the situation is available (knowledge gap); rather, it must be gained or created by the persons involved during the course of the process. In other words, it must evolve from scratch (closing the knowledge gap). Such processes are characteristic in that they are not continuously algorithmable and formalizable. Furthermore, such processes contain partial tasks that are new and occur only within these processes. Methods and tools, e.g. software tools and data, coming from a potential of methods and tools, e.g. method and data banks, must be provided in order to work on these tasks.

Complex, knowledge-intensive processes, especially problem-solving processes, require that the design and control of the cooperative work process are left to the participating individuals, who thus need to coordinate regarding cooperating participants, activities and responsibilities. This way, self-organised, dynamic (competence) networks are created in accordance with the requirements of a specific problem or process. 
The concept of self-organisation promises autonomy for those people in the work process. This is counteracted by an extraneous organisation (external determination), which is based on the determination of a process in advance (predefined sequence of activities) and leads to rigidly automated systems, which can be reduced by flexiblizing. In the reality of social organisations, permanent change between extraneous- and self-organisation takes place. This permanent change should be taken into account when designing and using systems for computer support of knowledge-intensive processes.

Rigid structures should be avoided when using computers in complex, self-organising social systems. Instead a flexible and dynamic support of information and communication processes should be aspired to. The permanent linking of syntactic (computer-based) and semantic (human) information processing and, simultaneously, the constant changing from an already organised system (function system) to a self-organising system (action system) is necessary.

Therefore, it is only possible to undertake a rough pre-structuring of the superordinate processes that can be structured (in advance). Tasks and activities within the pre-structured processes are not determined by the system or pre-defined. Instead, control of the work processes remains with the cooperating persons. Coordination amongst participants follows in accordance with the specific situation. Through dynamic selection of suitable cooperation partners and the possibility of including further partners if necessary, problem- and context-related knowledge and problem solution networks can evolve dynamically.

In order to depict complex organisational processes dynamically, the following are necessary:

a) interaction systems for communication and coordination amongst the participating persons,

b) spport systems for providing a potential of methods and data, e.g. for structuring workflows, finding suitable cooperation partners, possibility to access knowledge already available (organisational memory systems) etc. and

c) methods for integrating computer operations (support systems) in human interaction and activity

These need to be integrated such that the process can be supported as a dynamic network.

Such support is possible using synchronous telecooperation systems. On the one hand, they enable support of social interaction using communication tools (interaction system) such as audio and video. On the other, they enable the integration of computer operations (function systems) in human activity using cooperation tools such as application sharing and shared applications. 
Creating the unity of syntactic and semantic information processing and combining self-organisation and extraneous-determination in a sensible manner are the primary tasks of designing and using information and communication systems to support knowledge-intensive processes. (Synchronous) telecooperation systems can be used so that they will support a human capabilities, and are so flexible that organisational processes can be developed from the inside, meaning that they hamper the self-organisation of social systems less. People, being the only creative productive force, must remain involved in work processes as carriers and creators of knowledge.

\section{CONCLUSION \& SUMMARY}

The decentralised and networked utilization of modern information technologies, the development.of formal theories for documentation retrieval, to use the new technologies, agrees with the general development of the cognitivistic understanding of cognition and thus with its paradigm of information processing. However, the limitations of the information processing approach become clear also here.

The information- processing paradigm differentiates insufficiently or not at all between the reception of șignals, the manipulation of signs and the generation of meanings in the process of self-organisation.

The epistemological and methodological implications of the conception of creativity, of Information processing and information generation in the process of self-organisation, can influence our human choice.

The new work and organisation forms developing on basis of the information and communication technologies have ambivalent effects.

It is shown, that modern information and communication technologies disburden from formalized routine and support the reunion of formerly (tayloristic) separate activities (competence profit). At the same time, however, they can lead to raised monotony and the destruction of work (devaluation of human labour). By speaking of qualified e-work however, a lower demand or monotony of the work can hardly be expected; on the contrary, a competence profit is likely to be the result. However, this can also lead to an overtaxing. Such a mismatch between the performing person and his work can in consequence result in a "burnout" situation. This can lead in turn to a decrease in work quality, as well as to health problems. That is why the problem of "job burnout" is becoming an issue of increasing concern in today's working world, especially given the major costs it can produce for both employees and organisations [Maslach \& Leiter 1997].

The conventional view is, that burnout is primarily a problem of individuals, because of personal capabilities, character or behaviour. 
However, investigations show that burnout is not an individual problem, but rather a major sign of dysfunction within the organisation From the view of an integrated design of technology, work and organisation, it is a systems design problem to avoid the negative and to promote the positive effects like competence development of the individual and the organisation.

This can be achieved not only by closer integration of work and (predetermined) learning contents, but particularly by learning that is the result of activities performed in the concrete work process. This type of competence promoting work requires qualifying work content, and in particular complete, challenging, and integrated tasks [cf. Hacker 1991, Ulich 1992]. However, in addition to competence promoting work contents autonomy in fulfilling and improving the work tasks is necessary. The development of on-the-job competence requires an orientation toward the potentials of the self-organisation [Erpenbeck \& Heyse 1999].

We all have the opportunity to make human choices about the quality of jobs created, what kind of working environment will be designed, about new forms of organisations, about what our future will be like. The choice we make today will create the world in which we will live tomorrow.

\section{REFERENCES}

[Brier 1994]

[Brier 1996]

[Erpenbeck \& Heyse 1999]

[F. Fuchs-Kittowski 2001]

[F. Fuchs-Kittowski et al. 1998a]
Brier, S. (1994): What is a Possible Ontological and Epistemeological Framework for a True Universal 'Information Science'? - The Suggestion of a Cybersemiotics. In: Hofkichner, Wolfgang (Ed.): The Quest For A Unified Theory of Information, World Futures General Evolution Studies, Volume 13, Gordon and Breach Publishers, Australia, Cannada, Amsterdam.

Brier, S. (1996): The Usefulness of Cybersemiotics in Dealing with Problems of Knowledge Organization and Document Mediating Systems. In: Cybernetica Vol. XXXIX, N 4.

Erpenbeck, John; Heyse, Volker (1999): Die Kompetenzbiographie. Waxmann Verlag.

Fuchs-Kittowski, Frank (2001): Wissens-Ko-Produktion und dynamische Netze - Kooperative Wissenserzeugung und -nutzung in wissensintensiven Geschäftsprozessen. In: Schnurr, H.; Staab, S.; Studer, R.; Stumme, G.; Sure, Y. (Hrsg.): Professionelles Wissensmanagement - Erfahrungen und Visionen. Aachen: Shaker Verlag.

Fuchs-Kittowski, F.; Fuchs-Kittowski, K.; Sandkuhl, K. (1998): The use of synchronous telecooperation to design virtual, creative organisations - Conclusions based on empirical re-search. Poster presentation at the XV. IFIP World Computer Congress "The Global Information Society" Vienna/Austria and Budapest/Hungary, 31 August - 4 September 1998. 
[F. Fuchs-Kittowski Fuchs-Kittowski, F.; Fuchs-Kittowski, K.; Sandkuhl, K. (1998): et al. 1998b] Synchrone Telekooperation als Baustein für virtuelle Unternehmen - Schlussfolgerungen aus einer empirischen Untersuchung. In: Herrmann, T.; Just-Hahn, K. (Hrsg.): Groupware und organisatorische Innovation (D-CSCW'98), Stuttgart: B.G. Teubner, S. 19-36.

[K, Fuchs-Kittowski Fuchs-Kittowski. K., Lemgo, K., Schuster, U., Wenzlaff, B. (1975): et al. 1975]

Man Computer Communication: A Problem of Linking Semantic and Syntactic Information Processing. - In: Workshop on Data Communication. International Institute for Applied Systems Analysis 2361 Laxenburg, Austria, September 16-19, 1975, CP-769. S.169-188.

[K. Fuchs-Kittowski Fuchs-Kittowski, Klaus; Rosenthal, Hans-Alfred (1998): Information, et al. 1998c] Selbstorganisation und Evolution. Selbstorganisation, Information und Evolution - Zur Kreativität der lebenden Natur. In: Fenzel, Norbert; Hofkirchner, Wolfgang; Stockinger, Gottfried (Hrsg.): Information und Selbsbstorganisation - Annäherung an eine vereinheitlichte Theorie der Information, Studienverlag, Innsbruck, Wien, S. 141-188.

[K. Fuchs-Kittowski Fuchs-Kittowski, K.; Heinrich, L.; Rolf, A. (1999): Information et al. 1999a] entsteht in Organisationen - in kreativen Unternehmen. In: Becker, J.; König, W.; Schütte, R.; Wendt, O.; Zelewski, S. (Hrsg.): Wirtschaftsinformatik und Wissenschaftstheorie - Bestandsaufnahme und Perspektiven. Wiesbaden: Gabler, S. 331-361.

[Frei et al. 1996] Frei, Felix; Hugentobler, Margrit; Alioth, Andreas; Duell, Werner; Ruch, Luzian (1996): Die kompetente Organisation - Qualifizierte Arbeitsgestaltung - die europäische Alternative. VdF Hochschulverlag AG an der ETH Zürich.

[Hacker 1991] Hacker, W. (1991): Projektieren von Arbeitstätigkeiten. In: Zeitschrift für Arbeitswissenschaft, 4, S. 193-198.

[Jenkins 19981] Jenkins, David (1981): QWL - Current trends and directions. In: Issues in the Quality of Working Life, Ontario Ministry of Labour.

[Krogh 2000] Krogh, Georg von; Ichijo, Kazua; Nonaka, Ikujiro (2000): Enabling Knowledge Creation. Oxford University Press Inc.

[Mansell 1983] Mansell, Jacquie; Rankin, Tom (1983): Changing organisation - the quality of working life process. In: Issues in the Quality of Working Life, Ontario Ministry of Labour.

[Maslach \& Leiter Maslach, C.; Leiter, M. P. (1997): The Truth About Burnout. San 1997]

[Simon 1997]

[Trist 1981]

[Ulich 1992] Francisco, CA; Jossey-Bass.

Simon, H. A. (1997): The Sciences of the Artificial. 3rd ed., Cambridge, MA: The MIT Press, 1997.

Trist, Eric (1981): The evolution of socio-technical systems - a conceptual framework and an action research program. In: Issues in the Quality of Working Life, Ontario Ministry of Labour.

Ulich, Eberhard (1992): Arbeitspsychologie Schäffer-Pöschel Verlag, Stuttgart. 